\title{
Evaluation of Efficacy and Safety of Oral Olmesartan+ Chlorthalidone Combination in the Management of Hypertension in Indian Patients
}

\author{
ASHOK KHANNA, ${ }^{1}$ A. A. FARUQUI ${ }^{2}$
}

\begin{abstract}
Hypertension is the most prevalent chronic disease in India and its prevalence is rapidly increasing among urban and rural populations. Reducing blood pressure can decrease cardiovascular risk and all cause mortality. This study was conducted to assess the efficacy and safety of fixed dose combination of Olmesartan $40 \mathrm{mg}$ and Chlorthalidone I2.5mg. 30 hypertensive patients having systolic blood pressure $\geq 160 \mathrm{mmHg}$ and diastolic blood pressure $\geq 100 \mathrm{mmHg}$ who were uncontrolled on monotherapy with olmesartan were enrolled in this study.The treatment period was of 60 days and patients were administered once daily fixed dose combination of Olmesartan $40 \mathrm{mg}$ and Chlorthalidone $12.5 \mathrm{mg}$. Patients were evaluated on $15^{\text {th }}, 30^{\text {th }}$ and $60^{\text {th }}$ days of treatment. There was statistically significant $(p<0.000 \mathrm{I})$ decrease in systolic blood pressure from baseline to $15^{\text {th }}, 30^{\text {th }}$ and $60^{\text {th }}$ day of treatmentmean $\pm S D(I 79.1 \pm 13.38$ $\mathrm{mmHg}$ vs. $169.3 \pm 13.05,154.3 \pm 13.31$, and $142.7 \pm 6.91 \mathrm{mmHg}$ ) respectively. Similarly the diastolic blood pressure $(D B P)$ was significantly $(P<0.0001)$ reduced from the baseline to the $15^{\text {th }}, 30^{\text {th }}$ and $60^{\text {th }}$ day of treatment $(94.97 \pm 5.75 \mathrm{mmHg} v$ s.86.67 $\pm 4.79,80.33 \pm 1.82$ and $76.7 \pm 4.32 \mathrm{mmHg}$ respectively). Thus fixed dose combination of Olmesartan and Chlorthalidonewas found to be effective and safe option for the optimal management of hypertension.
\end{abstract}

Key words: Diastolic, Systolic, Blood Pressure, Hypertension, Fixed dose combination.

\section{Introduction}

The prevalence of hypertension is highly variable among population worldwide. Although control of hypertension has improved substantially over the past decade, $31 \%$ of people who are treated for hypertension are not controlled to a blood pressure (BP) level 140/90 mmHg. ${ }^{1}$

The Eighth Report of the Joint National Committee on Prevention, Detection, Evaluation, and Treatment of High Blood Pressure (JNC8) defines hypertension as blood pressure (BP) greater than $140 / 90 \mathrm{mmHg}$ in adults 18 years and older.

Epidemiological studies conducted in many parts of the world have consistently identified Hypertension strongest modifiable global risk factor for cardiovascular morbidity, mortality as well as health burdens. ${ }^{2}$

Clinical studies demonstrate that prevalence of hypertension is increasing rapidly among Indian urban and rural populations. In India, the situation is more alerting as hypertension attributes for nearly $10 \%$ of all deaths.

1. Consulting Physician, Jabalpur, India

2. Clinical Pharmacologist, India

Corresponding author:Dr. A. A. Faruqui, Clinical Pharmacologist, India. Email: drfaruqui@gmail.com.
Prevalence of hypertension in India is reported to vary from $4-15 \%$ in urban and $2-8 \%$ in rural population. ${ }^{3}$ It is estimated that the worldwide prevalence of hypertension would increase from $26.4 \%$ in 2000 to $29.2 \%$ in $2025 .{ }^{4}$ Therefore, there is a need for more effective antihypertensive regimens that include simple single-pill fixed-dose combination (FDC) products.

The European Society of Hypertension and Cardiology, states that the primary goal of treatment is to achieve the maximum reduction in long-term total risk of cardiovascular morbidity and mortality. ${ }^{5}$

More than $50 \%$ patients who do not response on monotherapy; require combination therapy for appropriate control of BP. ${ }^{6}$

Targets are achieved in only a limited number of patients using monotherapy. Since hypertension is multifactorial disease, most patients require two or more antihypertensive agents with different mechanisms of action for the optimal management. ${ }^{5,7}$

This approach is also recommended by the Joint National Committee (JNC VIII)on Prevention, Detection, Evaluation, and Treatment of High Blood Pressure 


\section{Materials and Methods}

This study was a post marketing, non-randomized, open, noncomparative,mono centric study. The fixed dose combination of Olmesartan $40 \mathrm{mg}$ and Chlorthalidone $12.5 \mathrm{mg}$ was administered to hypertensive patients once daily for 2 months (60 days). Informed consent was taken from the patients \& the post marketing surveillance was in accordance with the principles in declaration of Helsinki and Good Clinical Practice (GCP).

\section{Inclusion Criteria}

Both male and female hypertensive patients aged $>25$ years old with seated cuff $\geq 160 \mathrm{mmHg}$ and DBP $\geq 100 \mathrm{mmHg}$ and who were willing to give informed consent were included.

\section{Exclusion Criteria}

Patients with any condition which in the opinion of the investigator makes the patient unsuitable for inclusion like; known or suspected secondary hypertension, history of asthma or angina, female patient who was pregnant or willing to get pregnant, and patients with known hypersensitivity to any of the ingredient of the fixed dose combination were excluded from the study.

\section{Patient Distribution}

Out of 30 patients 18 were female and 12 were male patients in the age range of 25-92years old (Table 1).

\section{Efficacy and safety evaluations}

To evaluate the Efficacy following parameters were observed.

Primary outcome measures: Systolic Blood Pressure (SBP) and Diastolic Blood Pressure(DBP) were included in primary outcome, which were evaluated at $15^{\text {th }}, 30^{\text {th }}$ and $60^{\text {th }}$ day of treatment.

Secondary outcome measures: Global assessment of efficacy and safetywere included in this outcome \& patients achieving the goal set by JNC VIII that is $<150 / 90$ for elder patients aged above 60 year and 140/90 for those aged less than 60 years.

Global assessment regarding safety was evaluated by recording any adverse event or any complaint during the therapy during every visit. Safety outcomes include mainly symptoms related to hypotension like blurred vision, confusion, dizziness, nausea, vomiting, weakness or any other untoward effects. Patients were interviewed and asked about the type of adverse events throughout the study.

\section{Statistical analysis}

Data analysis on patient demographics and various outcome measures were performed using graph pad prism 6 . Comparison between the baseline values with the value on the $15^{\text {th }}, 30^{\text {th }}$ and $60^{\text {th }}$ day of treatment were made, as well as comparison in between these days were made by applying one way analysis of variance \& the Turkeys multiple comparison test. Value of $\mathrm{P}<0.05$ were considered as significant.

\section{Results}

SBP and DBP were recorded. In addition, overall efficacy and tolerability was assessed at the end of the study period. The baseline characteristics of patients are summarized in the Table 1 .

Table 1

Baseline characteristics of all patients

\begin{tabular}{lc}
\hline Male/Female (n) & $12 / 18$ \\
Age $(\mathrm{yrs})$ range & $25-92$ \\
Number of patients $>60$ years & 14 \\
Number of patients $<60$ years & 16 \\
SBP $($ Mean \pm SD)mm Hg & $179.1 \pm 13.38$ \\
DBP $($ Mean \pm SD)mm Hg & $94.9 \pm 5.75$ \\
\hline
\end{tabular}

\section{Systolic Blood Pressure (SBP)}

The SBP was measured at base line and then subsequently at $15^{\text {th }}, 30^{\text {th }}$ and $60^{\text {th }}$ days of treatment. The baseline $\mathrm{SBP}($ Mean $\pm \mathrm{SD})$ was $179.1 \pm 13.38 \mathrm{mmHg}$. The mean SBP at $15^{\text {th }}, 30^{\text {th }}$ and $60^{\text {th }}$ days of treatment were $169.3 \pm 13.05 \mathrm{mmHg}, 154.3 \pm 13.31 \mathrm{mmHg}$ and $142.7 \pm 6.91$ $\mathrm{mmHg}$ respectively. There was statistically highly significant $(p<0.0001)$ decrease in SBP from the baseline to the $15^{\text {th }}$, $30^{\text {th }}$ and $60^{\text {th }}$ day of treatment (Table 2, Fig. 1). SBP decreased by $9.8 \pm 0.33 \mathrm{mmHg}, 24.8 \pm 0.07 \mathrm{mmHg}$ and$36.4 \pm 6.47 \mathrm{mmHg}$ from the baselineto $15^{\text {th }}, 30^{\text {th }}$ and $60^{\text {th }}$ day of treatment respectively.(Table 4, Fig. 3)

Table -II

Effect of drug therapy on SBP

\begin{tabular}{lcccc}
\hline & Baseline & Day $15^{*}$ & Day $30^{* * * \$}$ & Day $60^{* * * \$}$ \\
\hline Mean \pm SD mmHg & $179.1 \pm 13.38$ & $169.3 \pm 13.05$ & $154.3 \pm 13.31$ & $142.7 \pm 6.91$ \\
\hline
\end{tabular}

$* * * \mathrm{p}<0.0001$ vs. baseline, $* \mathrm{p}<0.01$ vs. Baseline, $\$ \mathrm{p}<0.0001$ vs. Day 15 


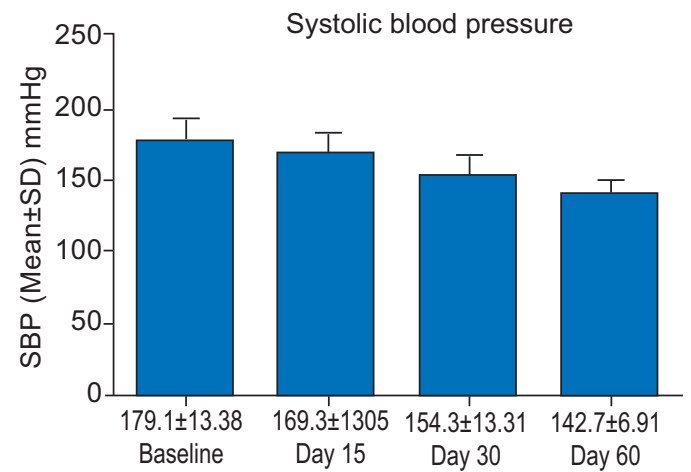

Fig.-1: Changes in systolic blood pressure

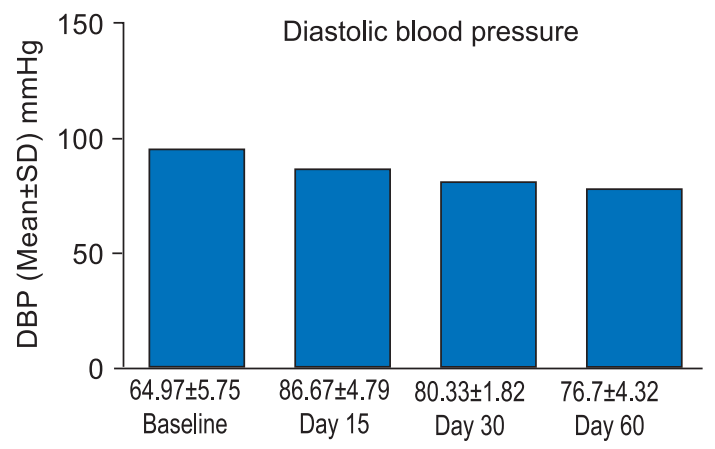

Fig.-2: Changes in diastolic blood pressure

Table-III

Effect of drug therapy on DBP

\begin{tabular}{lcccc}
\hline & Baseline & Day 15*** & Day 30***\$ & Day 60***\$ \\
\hline Mean \pm SD mmHg & $94.97 \pm 5.75$ & $86.67 \pm 4.79$ & $80.33 \pm 1.82$ & $76.7 \pm 4.32$ \\
\hline
\end{tabular}

$* * * p<0.0001$ vs. baseline, ${ }^{\$} p<0.0001$ vs. day $15^{\text {th }}$

\section{Diastolic Blood Pressure (DBP)}

The DBP was measured at base line and then subsequently at $15^{\text {th }}, 30^{\text {th }}$ and $60^{\text {th }}$ days of treatment. The baseline $\mathrm{DBP}($ Mean \pm SD) was $94.97 \pm 5.75 \mathrm{mmHg}$. The mean DBP at $15^{\text {th }}, 30^{\text {th }}$ and $60^{\text {th }}$ days of treatment were $86.67 \pm 4.79$ $\mathrm{mmHg}, 80.33 \pm 1.82 \mathrm{mmHg}$ and $76.7 \pm 4.32$ respectively. There was statistically highly significant $(\mathrm{p}<0.0001)$ decrease in DBP from the baseline to the $15^{\text {th }}, 30^{\text {th }}$ and $60^{\text {th }}$ day of treatment (Table 3, Fig. 2). DBP decreased by $8.3 \pm 0.96 \mathrm{mmHg}, 14.64 \pm 3.93 \mathrm{mmHg}$ and $18.27 \pm 1.43 \mathrm{mmHg}$ from the baseline to $15^{\text {th }}, 30^{\text {th }}$ and $60^{\text {th }}$ day of treatment respectively.(Table 4, Fig. 3 ).

Table-IV

Change in SBP and DBP from the baseline (Mean $\pm S D$ $\mathrm{mmHg}$ )

\begin{tabular}{lccc}
\hline BP & Day 15 & Day 30 & Day 60 \\
\hline "SBP & $-9.8 \pm 0.33$ & $-24.8 \pm 0.07$ & $-36.4 \pm 6.47$ \\
"DBP & $-8.3 \pm 0.96$ & $-14.64 \pm 3.93$ & $-18.27 \pm 1.43$ \\
\hline
\end{tabular}

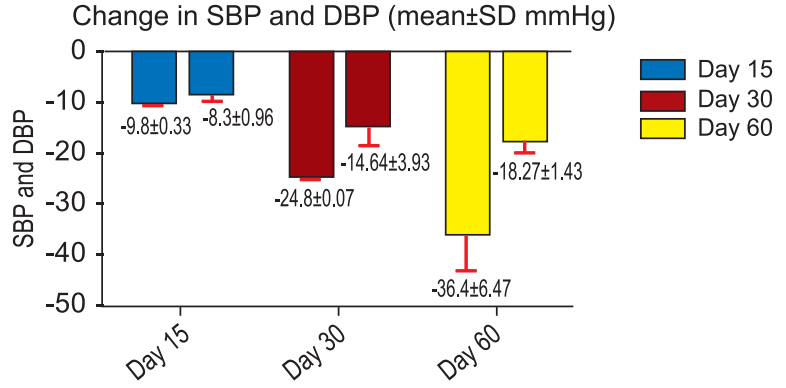

Fig.-3 : Changes in systolic \& diastolic blood pressure

\section{Achievement of JNC VIII goal}

As per JNC VIII recommended target goal for patients $>60$ years old is $150 / 90 \mathrm{mmHg}$ and $140 / 90 \mathrm{mmHg}$ for patients of age $<60$ years. During and after the treatment following are the percentage of patients achieving the target BP goal. (Table 5)

Table -V

Percentage of patients ( $>60$ years and $<60$ years) achieving the target BP respectively $<150 / 90 \mathrm{mmHg}$ and $<140 / 90$ $\mathrm{mmHg}$

\begin{tabular}{lccc}
\hline & Day 15 & Day 30 & Day 60 \\
\hline$\%$ of patients $(\mathrm{n})>60$ years & $(02 / 14) 14.28 \%$ & $(07 / 14) 50.00 \%$ & $(14 / 14) 100.00 \%$ \\
$\%$ of patients $(\mathrm{n})<60$ years & $(02 / 16) 12.50 \%$ & $(05 / 16) 31.25 \%$ & $(16 / 16) 100.00 \%$ \\
\hline
\end{tabular}




\section{Global Assessment of Safety}

Treatment was well tolerated and 3 out of 30 patients (10

$\%$ ) complained about the side effects like headache, general weakness and dizziness.

\section{Discussion}

The prevalence of hypertension has risen dramatically in last three decades hence appropriate antihypertensive drug therapy is important. ${ }^{8}$

Treatment goal of Hypertension is to control BP with minimum complications and adverse effects that improve the patient's quality of life. European guidelines and many other guidelines suggest the need of fixed dose combination therapy for the treatment of hypertension. ${ }^{7,9} \mathrm{On}$ the basis of epidemiological studies using fixed dose combinations in a single pill represents in improving the control of hypertension and are efficient to achieve target goal of BP with no safety issues. ${ }^{10,11}$

Combination has synergistic and complementary mechanism of action and higher efficacy compared to monotherapy. ${ }^{9}$ Ample evidences are available from the different clinical studies that multiple antihypertensive therapies are often required for effective control of blood pressure.

A clinical benefit of fixed drug combination in the management of hypertension has been already established. This study was conducted to evaluate the efficacy and safety of fixed dose combination of Olmesartan and Chlorthalidone in Indian patients.

There are no published studies of olmesartan in combination with chlorthalidone thus the results of the present study have shown encourage state with regard to the reduction in both SBP/DBP and in the achievement of target goal. Side effects were mild in natureand did not require discontinuation of therapy. Overall no safety concern for treatment was identified.

\section{Conclusion}

Fixed dose combination therapy of Olmesartan and Chlorthalidoneis an effective, safe and convenient treatment approach in controlling the blood pressure and achieving the desired blood pressure goal according to JNC VIII with patient adherence and compliance.

\section{Acknowledgments}

Authors acknowledge the immense help received from the scholars whose articles are cited and included in references of this manuscript. The authors are also grateful to Mr.ShaileshPallewar(M.Pharm-Pharmacology) for doing the statistical analysis.

\section{Conflict of Interest : None}

\section{References}

1. Egan BM, Zhao Y, Axon RN. US trends in prevalence, awareness, treatment, and control of hypertension, 19882008. JAMA. 2010;303:2043-2050.

2. Kokiwar PR, Gupta SS, Durge PM. Prevalence of hypertension in a rural community of central India. J Assoc Physicians India. 2012;60:26-29.

3. Sandozi T, EmaniVK. Survey of prescription pattern of antihypertensivedrugs in hypertensives \& hypertension associated diabetics. International Journal of Pharma and Bio Sciences. 2010;1(4):P23-26.

4. Kearney PM, Whelton M, Reynolds K, Muntner P, WheltonPK, He J. Global burden hypertension: analysis of worldwide data. Lancet. 2005;365:217-23.

5. Mancia G, De Backer G, Dominiczak A; Guidelines for the Management of Arterial Hypertension: The Task Force for the Management of Arterial Hypertension of the European Society of Hypertension (European Society of Hypertension) and of the European Society of Cardiology (ESC). J Hypertens. 2007; 25(6):1105-1187.

6. Norris K, NeutelJM; Emerging Insights in the First-Step Use of Antihypertensive Combination Therapy. J Clin Hypertens (Greenwich) 2007, 9(12 Suppl 5):5-14.

7. Mancia G, Laurent S, Agabiti-Rosei E; Reappraisal of European guidelines on hypertension management: a European Society of Hypertension Task Force document. J Hypertens. 2009; 27(11): 2121-2158.

8. Gupta R. Trends in hypertension epidemiology in India. J Hum Hypertens. 2004;18:73-78.

9. Law MR, Morris JK, Wald NJ; Use of blood pressure lowering drugs in the prevention of cardiovascular disease: meta-analysis of 147 randomised trials in the context of expectations from prospective epidemiological studies. BMJ, 2009; 338:b1665.

10. Alleman Y, Fraile B, Lambert M, Barbier M, Ferber P, IzzoJL Jr. Efficacy of the combination of amlodipine and valsartan in patients with uncontrolled hypertension with previous monotherapy: The Exforge in previous failure after single therapy (EX-fast) study. J Clin Hypertens.2008;10:185-194.

11. PoolJL, GlazerR, Weinberger M, Alvarado M, Huang J, Graff. A. Comparison of valsartan/hydrochlorothiazide combination therapy at doses up to $320 / 25$ versus monotherapy: a double blind placebo controlled study followed by long-term combination therapy in hypertensive adults. ClinTher. 2007;29:61-73. 